\title{
Synthesis of a One-Dimensional Coordination Polymer of Nickel(II) Complex with a $\beta$-Oxodithioester Ligand
}

\author{
Ricardo Rosas-Reyes, ${ }^{1}$ Yasmi Reyes-Ortega, ${ }^{2}$ T. Jesus Morales-Juarez, \\ Virginia Gómez-Vidales, ${ }^{4}$ and Ivan García-Orozco ${ }^{1}$ \\ ${ }^{1}$ Laboratorio de Investigación y Desarrollo de Materiales Avanzados (LIDMA), Facultad de Química, \\ Universidad Autónoma del Estado de México, Carretera Toluca-Atlacomulco Km 14.5, Unidad San Cayetano, Toluca, MEX, Mexico \\ ${ }^{2}$ Centro de Química, ICUAP, Benemérita Universidad Autónoma de Puebla, CU, 72570 Puebla, PUE, Mexico \\ ${ }^{3}$ Facultad de Química, Universidad Autónoma del Estado de México, Paseo Colón esq. Paseo Tollocan s/n, 50120 Toluca, MEX, Mexico \\ ${ }^{4}$ Instituto de Química, Universidad Nacional Autónoma de México, Circuito Interior, Ciudad Universitaria, Coyoacán, \\ 01450 Mexico City, Mexico
}

Correspondence should be addressed to Ivan García-Orozco; igarciao@uaemex.mx

Received 31 May 2017; Revised 11 September 2017; Accepted 14 September 2017; Published 30 October 2017

Academic Editor: Henryk Kozlowski

Copyright ( 2017 Ricardo Rosas-Reyes et al. This is an open access article distributed under the Creative Commons Attribution License, which permits unrestricted use, distribution, and reproduction in any medium, provided the original work is properly cited.

\begin{abstract}
Bis-[methyl-1-hydroxy-1-cyclopentene-2-dithiocarboxylate-O,S]nickel(II) $\mathbf{1}$ was prepared starting from methyl 2-hydroxycyclopent-1-encarbodithioate ligand (CPDT) and $\mathrm{Ni}(\mathrm{II})$, and catena- $\left[\left(\mu_{2}-4,4^{\prime}\right.\right.$-Bipyril)-bis-(methyl-2-hydroxy-1-cyclopentene-2dithiocarboxylate-O,S)]nickel(II) 2 was prepared in good yields from 1 plus $4,4^{\prime}$-bipyridyl (bpy) by shish-kebab methodology. The structure of 1 was confirmed by FTIR, elemental analysis, ${ }^{1} \mathrm{H}$ NMR, UV-vis in chloroform solution and in solid, XPS, and PXRD. Compound 2 was characterized by FTIR, elemental analysis, UV-vis in chloroform solution, and in solid, XPS, PXRD, ESR, and solid state magnetization measurements. The structure of the polymer was established mostly by PXRD, ESR, and magnetization.
\end{abstract}

\section{Introduction}

Discrete metallosupramolecular assemblies have been prepared towards potential applications in catalysis, gas-storage, separation, sensing, magnetism, optics, and electrochemistry, among others [1-6]. The design of well-defined structures is based on the directional-bonding approach, using rigid ligands with highly directional coordinating groups and geometrically constrained metals entities. In this sense, the wheel-and-axle approach is being applied to obtain $1 \mathrm{D}$ polymers [7], which are also described as shish-kebab coordination polymers $[8,9]$. This type of linear supramolecules is formed when an ambidentate ligand bridges metalloporphyrins with hexacoordinated metals [10]. Shish-Kebab approach has three variables (macrocycle, bridging group, and transition metal) wherein metalloporphyrins were commonly used as macrocycle-metal moiety, and $N, N^{\prime}$-bidentate ligands perform as bridging group, towards the control of optical, magnetic, and electrical properties [11].
Not only are metalloporphyrins used in shish-kebab coordination polymers, but square planar complexes with two vacancies have also been used to obtain $1 \mathrm{D}$ coordination polymers [12-14]. We are interested in nickel(II) complexes with O,S-donor ligands and in the study of the structure and chemical properties given by the S-donor atoms in the nickel coordination sphere. Dorange et al. reported the synthesis of the $\mathrm{NiL}_{2}$ diamagnetic complex ( $\mathrm{L}=$ methyl 3hydroxy-3-phenyl-2-propenedithioate) [15] and a paramagnetic $\left[\mathrm{NiL}_{2}(\mathrm{Py})_{2}\right]$ bis-pyridine derivative. This work shows the possible use of bis-chelated complexes in square planar structure for the preparation of shish-kebab coordination polymer with a $4,4^{\prime}$-bipyridyl bridge. Herein we report the syntheses and structural characterization of two nickel(II) complexes bis-[Methyl 1-hydroxy-1-cyclopentene-2-dithiocarboxylate-O,S] nickel(II) 1 and catena- $\left[\left(\mu_{2}-4,4^{\prime}\right.\right.$-bipyridyl)-bis-(methyl 2-hydroxy-1-cyclopentene-2-dithiocarboxylate-O,S)nickel(II)] 2, starting from methyl 2-hydroxycyclopent-1-encarbodithioate ligand [16] and its $1 \mathrm{D}$ coordination 
polymer bridged by bpy. The structure of the latter was evidenced by spectroscopy in solid state, being unstable in solution.

\section{Experimental Section}

2.1. Materials and Methods. Cyclopentanone, methyl iodide, potassium tert-butoxide, 4,4'-bipyridyl (Aldrich), carbon disulfide, and nickel(ii) chloride (J. T. Baker) were used without further purification. Solvents were distilled before use. Melting points were determined in a Melt-temp II. ${ }^{1} \mathrm{H}$ and ${ }^{13} \mathrm{C}$ NMR spectra were recorded using a Bruker-Advance $300 \mathrm{MHz}$ spectrometer, using TMS as internal standard. IR spectra were recorded on a Nicolet Avatar 360 in $\mathrm{KBr}$ and ATR FT-IR Shimadzu, IR Prestige-21 model with $4 \mathrm{~cm}^{-1}$ of resolution. Electronic absorption spectra were obtained on a Perkin Elmer lambda 25 spectrophotometer. The XPS spectra were acquired using a JEOL JPS-9200, equipped with a $\mathrm{Mg}$ $\mathrm{X}$-ray source $(1253.6 \mathrm{eV})$ at $200 \mathrm{~W}$; the area of analysis was $1 \mathrm{~mm}$, and the vacuum was in the order of $10^{-8}$ Torr for all samples. The spectra were analyzed using the SpecSurf software included with the instrument; all spectra were charge-corrected using the carbon signal (C 1s) at $284.5 \mathrm{eV}$ as a reference. The Shirley method was used for the background subtraction, while in the curve fitting process the GaussLorentz method was used. Electron Paramagnetic Resonance spectra were recorded on JOEL JES-TE300 of 1.4 T spectrometer, operated on X-band at FM $100 \mathrm{KHz}$ in cylindrical cavity on TE011 method. The samples were handled as solid into Wilmad quartz tubes. Magnetization measurements were performed with a Quantum Design MPMS SQUID magnetometer, MPMS-5. Field-cooling (FC) cycle was performed at magnetic field intensity of 1000 Oe in the range 2 up to $300 \mathrm{~K}$. Powder X-ray diffraction data were acquired in a Bruker D8 advance diffractometer equipped with a Linxeye detector, using $\mathrm{Ni}$-filtered $\mathrm{Cu} \mathrm{K} \alpha$ radiation. Tube conditions were $30 \mathrm{kV}, 30 \mathrm{~mA} ; 2 \theta$ range $5-50^{\circ}$; step size $0.02^{\circ}$; step time $32 \mathrm{~s}$.

2.2. Synthesis of the Methyl 2-Hydroxycyclopent-1-encarbodithioate Ligand (CPDT). To potassium tert-butoxide $(8.3 \mathrm{~g}$, $74 \mathrm{mmol}$ ) in $200 \mathrm{~mL}$ of dry ethyl ether was added cyclopentanone $(3 \mathrm{~mL}, 34 \mathrm{mmol})$ under stirring at $-10^{\circ} \mathrm{C}$. After 30 minutes, a solution of $\mathrm{CS}_{2}(2.2 \mathrm{~mL}, 36 \mathrm{mmol})$ in the same solvent $(20 \mathrm{~mL})$ was added, continuing the stirring for $1.5 \mathrm{~h}$ more. Methyl iodide $(2.2 \mathrm{~mL}, 36 \mathrm{mmol})$ was then added and a reddish suspension was obtained. The solvent was removed under vacuum, the solid was dissolved in water and acidified with $\mathrm{HCl} 2 \mathrm{M}$, extracted with $\mathrm{CH}_{2} \mathrm{Cl}_{2}$, dried by $\mathrm{Na}_{2} \mathrm{SO}_{4}$, and concentrated. A yellow crystalline solid was obtained by silica-gel chromatography using hexane as eluent. Yield: $3.15 \mathrm{~g}(53 \%)$, mp: $37.6^{\circ} \mathrm{C}$. IR $\left(\mathrm{KBr}, \mathrm{cm}^{-1}\right)$ : $3427 \mathrm{br}, 2924 \mathrm{~m}$, $2853 \mathrm{~m}, 1644 \mathrm{w}, 1553 \mathrm{~s}, 1523 \mathrm{~m}, 1447 \mathrm{~m}, 1423 \mathrm{w}, 1330 \mathrm{w}, 1242 \mathrm{~m}$, 1072 w, 1020 w, 984 w, 949 w, 789 w. IR $\left(\right.$ ATR, $\left.\mathrm{cm}^{-1}\right): 2953$ w, $2915 \mathrm{w}, 2851 \mathrm{w}, 1547 \mathrm{~s}, 1443 \mathrm{~m}, 1418 \mathrm{~m}, 1237 \mathrm{~m}, 793 \mathrm{~m} .{ }^{1} \mathrm{H}$ $\mathrm{RMN}\left(300 \mathrm{MHz}, \mathrm{CDCl}_{3}\right): \delta 1.89(\mathrm{q}, 2 \mathrm{H}, J=7.4,7.9 \mathrm{~Hz}$, $\mathrm{CH}_{2} \mathrm{CH}_{2} \mathrm{CH}_{2}$ ), 2.63 (s, $3 \mathrm{H}, \mathrm{SCH}_{3}$ ), 2.67 (t, $2 \mathrm{H}, J=7.9 \mathrm{~Hz}$, $\left.\mathrm{CH}_{2} \mathrm{C}_{2} \mathrm{C}=\right), 2.80\left(\mathrm{t}, 2 \mathrm{H}, J=7.4 \mathrm{~Hz}, \mathrm{C}(\mathrm{O}) \mathrm{C}_{2} \mathrm{CH}_{2}\right), 14.27(s$, $1 \mathrm{H}, \mathrm{OH}) .{ }^{13} \mathrm{C} \mathrm{NMR}\left(75 \mathrm{MHz}, \mathrm{CDCl}_{3}\right): \delta 16.79\left(\mathrm{SCH}_{3}\right), 18.39$

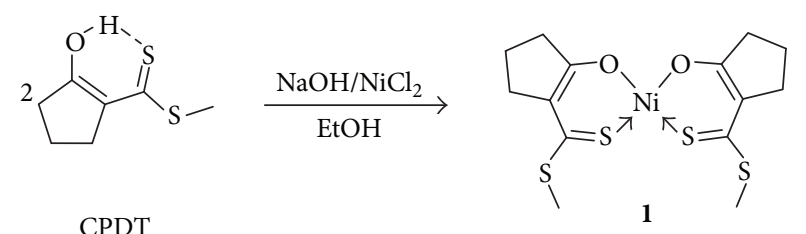

Scheme 1: Synthesis of $\mathbf{1}$ from CPDT ligand.

$\left(\mathrm{CH}_{2} \underline{\mathrm{CH}} \mathrm{H}_{2} \mathrm{C}=\right), 30.79\left(\mathrm{CH}_{2} \underline{\mathrm{CH}_{2}} \mathrm{CH}_{2}\right), 35.07\left(\mathrm{C}(\mathrm{O}) \underline{\mathrm{C}} \mathrm{H}_{2} \mathrm{CH}_{2}\right)$, $119.30\left(\mathrm{C}_{\mathrm{vin}}\right), 179.47(\mathrm{CO}), 213.63\left(\mathrm{CS}_{2}\right)$. UV-Vis $\left(\mathrm{CHCl}_{3}\right)$, $\left[\lambda_{\max } \mathrm{nm}\left(\varepsilon, \mathrm{M}^{-1} \mathrm{~cm}^{-1}\right)\right]: 319$ (17650), 354 (13450), 374 (17160).

2.3. Synthesis of bis-[Methyl 1-Hydroxy-1-cyclopentene-2-dithiocarboxylate-O,S] nickel(II) 1. An aqueous $\mathrm{NaOH}$ solution $(5 \mathrm{~mL}, 0.4 \mathrm{M})$ was added to a warm ethanolic solution of CPDT $(0.34 \mathrm{~g}, 1.95 \mathrm{mmol})$ under stirring. $\mathrm{NiCl}_{2} \cdot 6 \mathrm{H}_{2} \mathrm{O}$ $(0.24 \mathrm{~g}, 0.99 \mathrm{mmol})$ in $25 \mathrm{~mL}$ of ethanol was then added to the mixture, producing an orange solid. The precipitate was filtered and washed with ethanol and hexane, yielding $0.34 \mathrm{~g},(87 \%)$, mp: $\mathrm{d} 250^{\circ} \mathrm{C}$. Calc. for $\mathrm{C}_{14} \mathrm{H}_{18} \mathrm{NiO}_{2} \mathrm{~S}_{4} \cdot \mathrm{H}_{2} \mathrm{O}: \mathrm{C}$, 39.73; H, 4.76; S, 30.30. Found: C, 39.89; H, 4.31; S, 30.16. IR $\left(\mathrm{KBr}, \mathrm{cm}^{-1}\right): 2904 \mathrm{w}, 1546 \mathrm{~s}, 1406 \mathrm{~s}, 1287 \mathrm{~m}, 972 \mathrm{w}, 934 \mathrm{w}$, $910 \mathrm{~m}, 846 \mathrm{w}, 669 \mathrm{w}$. IR (ATR, $\mathrm{cm}^{-1}$ ): $2951 \mathrm{w}, 2908 \mathrm{w}, 2863 \mathrm{w}$, $1545 \mathrm{~s}, 1441 \mathrm{~s}, 1409 \mathrm{~s}, 1288 \mathrm{w}, 847 \mathrm{~m} .{ }^{1} \mathrm{H}$ RMN $(300 \mathrm{MHz}$, $\left.\mathrm{CDCl}_{3}\right): \delta 1.86\left(\mathrm{~m}, 2 \mathrm{H}, J=7.6,7.8 \mathrm{~Hz} \mathrm{CH} \mathrm{CH}_{2} \mathrm{CH}_{2}\right), 2.46$ $\left(\mathrm{t}, 2 \mathrm{H}, J=7.8 \mathrm{~Hz}, \mathrm{CH}_{2} \mathrm{CH}_{2} \mathrm{C}=\right), 2.59\left(\mathrm{~s}, 3 \mathrm{H}, \mathrm{SC}_{3}\right), 2.65(\mathrm{t}$, $\left.2 \mathrm{H}, J=7.6 \mathrm{~Hz}, \mathrm{C}(\mathrm{O}) \mathrm{CH}_{2} \overline{\mathrm{CH}}_{2}\right) . \mathrm{UV}-\mathrm{Vis}\left(\mathrm{CHCl}_{3}\right),\left[\lambda_{\max } \mathrm{nm}\right.$ $\left.\left(\varepsilon, \mathrm{M}^{-1} \mathrm{~cm}^{-1}\right)\right]: 238$ (28330), 245 (26260), 277 (25350), 313 (31160), 334 (25950), 378 (5600), 439 (4190). UV-Vis-NIR (solid), $\left[\lambda_{\max } \mathrm{nm}\right]: 405,513,705$.

2.4. Synthesis of catena-[( $\mu_{2}-4,4^{\prime}$-Bipyridyl)-bis-(methyl $2-H y$ droxy-1-cyclopentene-2-dithiocarboxylate-O,S)nickel(II)] 2. A solution of bpy $(0.08 \mathrm{~g}, 0.53 \mathrm{mmol})$ in $10 \mathrm{~mL}$ of $\mathrm{CHCl}_{3}$ was added to a $50 \mathrm{~mL}$ of chloroform solution of $1(0.104 \mathrm{~g}$, $0.25 \mathrm{mmol}$ ) under stirring at room temperature for $1 \mathrm{~h}$. The yellow solid was filtered, washed with $\mathrm{CHCl}_{3}$ and dried under vacuum. Yield $0.106 \mathrm{~g}$ (73\%), mp: $\mathrm{d} 270^{\circ} \mathrm{C}$. Calc. for $\mathrm{C}_{24} \mathrm{H}_{26} \mathrm{~N}_{2} \mathrm{NiO}_{2} \mathrm{~S}_{4} \cdot 0.25 \mathrm{CHCl}_{3}$ : C, 49.99, H, 4.58, S, 22.01, N, 4.81. Found: C, $49.85, \mathrm{H}, 4.46, \mathrm{~S}, 21.53, \mathrm{~N}, 4.71$. IR (ATR, $\left.\mathrm{cm}^{-1}\right)$ : $2874 \mathrm{w}, 2954 \mathrm{w}, 2911 \mathrm{w}, 2834 \mathrm{w}, 1575 \mathrm{~m}, 1483 \mathrm{~s}, 1419 \mathrm{~s}$, $1375 \mathrm{~s}, 1274 \mathrm{~m}, 801 \mathrm{~m}, 727 \mathrm{~m}, 625 \mathrm{~m}$. UV-Vis-NIR (solid), [ $\left.\lambda_{\max } \mathrm{nm}\right]: 441,614,876,928,1008$.

\section{Results and Discussion}

3.1. Synthesis and Characterization of $\mathbf{1}$. $\mathbf{1}$ was obtained according to similar methodology (Scheme 1) previously reported for the nickel complexes of the methyl 3-hydroxy$3\left(4^{\prime}\right.$-R-phenyl)-2-propenedithiocarboxylate ligands [15]. The proposed structure of $\mathbf{1}$ was built by its spectroscopic characteristics and single crystal analysis.

In the IR spectrum of $\mathbf{1}$, the loss of the centered band is observed at $3427 \mathrm{~cm}^{-1}$, which was assigned to $\mathrm{H}-\mathrm{O}$ enol group in the ligand. The signals at 1405 and $909 \mathrm{~cm}^{-1}$ were assigned to $\delta(\mathrm{C}-\mathrm{O})$. These signals were low energy-shifted 
TABLE 1: Deconvoluted UV-vis signals (nm) of compounds $\mathbf{1}$ and 2.

\begin{tabular}{|c|c|c|}
\hline Assignation & 1 & 2 \\
\hline \multicolumn{3}{|c|}{$\mathrm{CHCl}_{3}$ solution } \\
\hline$\pi^{*} \leftarrow n \mathrm{O}$ & 280 & 279 \\
\hline$\alpha, \beta$-unsat & 315 & 314 \\
\hline$\pi^{*} \leftarrow n \mathrm{CS}$ & 337 & 336 \\
\hline S-Ni LMCT & 384 & 378 \\
\hline O-Ni LMCT & 445 & 442 \\
\hline \multicolumn{3}{|c|}{ Solid } \\
\hline$\pi^{*} \leftarrow n \mathrm{CS}$ & 350 & 351 \\
\hline S-Ni LMCT & 399 & 406 \\
\hline \multirow[t]{3}{*}{ O-Ni LMCT } & 449 & 459 \\
\hline & 501 & 499 \\
\hline & 714 & \\
\hline${ }^{3} \mathrm{~T}_{1 \mathrm{~g}}(\mathrm{P}) \leftarrow{ }^{3} \mathrm{~A}_{2 \mathrm{~g}}\left(\nu_{1}\right)$ & & 571 \\
\hline${ }^{3} \mathrm{~T}_{1 \mathrm{~g}}(\mathrm{~F}) \leftarrow{ }^{3} \mathrm{~A}_{2 \mathrm{~g}}\left(\nu_{2}\right)$ & & 886 \\
\hline${ }^{3} \mathrm{~T}_{2 \mathrm{~g}}(\mathrm{~F}) \leftarrow{ }^{3} \mathrm{~A}_{2 \mathrm{~g}}\left(\nu_{3}\right)$ & 934 & 922 \\
\hline
\end{tabular}

respecting to the ligand $\left(1422\right.$ and $949 \mathrm{~cm}^{-1}, \Delta v=-17$ and $-39 \mathrm{~cm}^{-1}$, resp.) probably due to the O-Ni $\sigma$-donation. The stretching mode of thiocarbonyl group $(\mathrm{C}=\mathrm{S})$ is observed at $1286 \mathrm{~cm}^{-1}$ in the spectrum of $\mathbf{1}$, and this signal is high energy-shifted from ligand $\left(1242 \mathrm{~cm}^{-1}, \Delta \nu=44 \mathrm{~cm}^{-1}\right)$ [17]. This fact could be provoked to the back donation of electron density from nickel to ligand. The $\nu(\mathrm{C}=\mathrm{C})$ at $1545 \mathrm{~cm}^{-1}$ is shifted towards lower wavenumbers from those of the ligand $\left(1552 \mathrm{~cm}^{-1}, \Delta v=-7 \mathrm{~cm}^{-1}\right)$. The changes on $\mathrm{C}-\mathrm{O}, \mathrm{C}=\mathrm{S}$, and $\mathrm{C}=\mathrm{C}$ energy vibrations suggest the electron delocalization on the 6-membered chelated ring of the complex [17].

The ${ }^{1} \mathrm{H}$ NMR spectroscopy complements the structural information of 1 . The enol proton observed at $14.27 \mathrm{ppm}$ for CPDT ligand disappears in the spectrum of $\mathbf{1}$. In general, the rest of the signals are upfield-shifted compared to the ligand, except SMe protons, which are not significantly affected by coordination (2.63 ppm in CPDT). The multiplets at 1.87 , 2.46 , and $2.66 \mathrm{ppm}$ assigned to cyclopentene moiety are less shifted from the ligand (at 1.89, 2.68, and $2.81 \mathrm{ppm}$ in ligand, $\Delta \delta=-0.02,-0.22$, and $-0.15 \mathrm{ppm}$, resp.) due to the increase of electron delocalization by the coordination.

The chloroform UV-vis spectrum of 1 (Figure 1) shows electronic transitions in both UV and visible part of the spectrum (Table 1). In the UV range, two main absorption bands are observed corresponding to a ligand transition. Overall, the absorption bands are blue shifted respecting ligand by the nickel coordination. The band at $280 \mathrm{~nm}$ was assigned to the $\pi^{*} \leftarrow n$ transition of the oxygen atom. The band assigned to $\alpha, \beta$-unsaturated system centered at $315 \mathrm{~nm}$ has an important hyperchromic effect, evidencing the increase of $\pi$-conjugation in $\mathbf{1}$. The band at $337 \mathrm{~nm}$ was assigned to a $\pi^{*} \leftarrow n$ transition of dithiocarbonyl group. Two bands on the visible region at 383 and $445 \mathrm{~nm}$ may belong to S-Ni and O-Ni LMCT transitions $[18,19]$. In the solid electronic spectrum, the deconvoluted signal centered at 350 was assigned to a $\pi^{*} \leftarrow n$ transition of dithiocarbonyl group

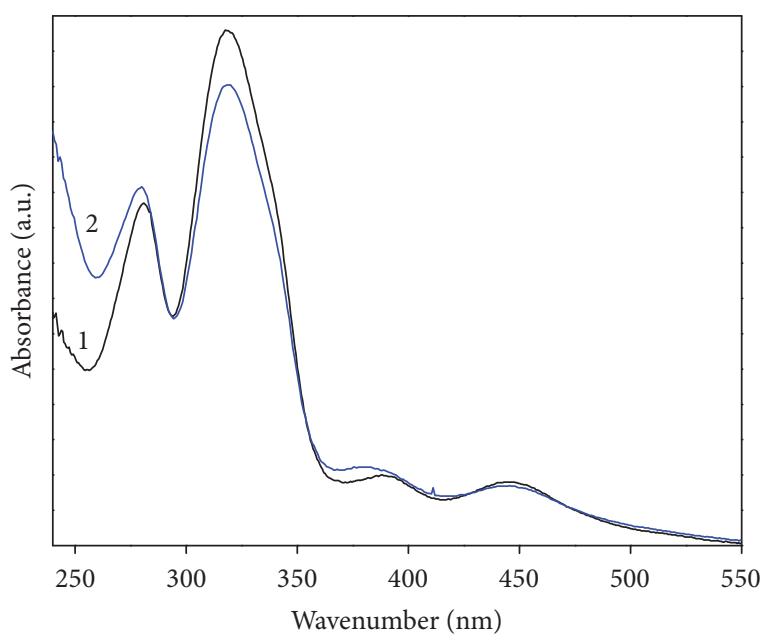

Figure 1: Absorption spectra of chloroform solution of $\mathbf{1}$ and $\mathbf{2}$, in chloroform.

(Figures S1-S6 in Supplementary Material available online at https://doi.org/10.1155/2017/7623210) and S-Ni and O-Ni LMCT transitions were observed at 399 and $449 \mathrm{~nm}$, and an additional band appears around $405 \mathrm{~nm}$ among two weaker bands at 501 and $714 \mathrm{~nm}$, which were assigned to ${ }^{1} \mathrm{~A}_{2 \mathrm{~g}} \leftarrow{ }^{1} \mathrm{~A}_{1 \mathrm{~g}}$ and ${ }^{1} \mathrm{~B}_{1 \mathrm{~g}} \leftarrow{ }^{1} \mathrm{~A}_{1 \mathrm{~g}}$, corresponding to a square planar geometry on nickel(II) center [20,21].

The XPS spectrum of 1 shows the presence of carbon, oxygen, sulfur, and nickel signals (Figure 2 and Table 2). The Ni $2 \mathrm{p}_{3 / 2}$ signal at $854.87 \mathrm{eV}$ (Table 1) could be assigned to a nickel(II) atom surrounded by O,S-donors similar to the reported $\left[\mathrm{Ni}\left(\mathrm{SC}\left(\mathrm{SCH}_{3}\right) \mathrm{CHC}\left(\mathrm{C}_{6} \mathrm{H}_{5}\right) \mathrm{O}\right)_{2}\right]$ complex, $(855.00 \mathrm{eV})$ [22]. The absence of satellite peaks confirms the diamagnetic behavior of nickel center and the square planar geometry of the complex. 
TABLE 2: Binding energies (eV) of the different components observed in XPS spectra for $\mathbf{1}$ and 2.

\begin{tabular}{lccr}
\hline BE $(\mathrm{eV})$ & $\mathbf{1}$ & $\mathbf{2}$ & Corresponding peak \\
\hline O 1s & 530.38 & 530.29 & O=C \\
& 531.99 & 531.92 & O-C \\
S 2p & 161.12 & 160.90 & $\mathrm{~S}=\mathrm{C} \mathrm{2p3/2}$ \\
& 162.04 & 161.81 & $\mathrm{~S}=\mathrm{C} \mathrm{2p1/2}$ \\
& 163.06 & 162.75 & $\mathrm{~S}-\mathrm{C} 2 \mathrm{p} 3 / 2$ \\
$\mathrm{Ni} 2 \mathrm{p}$ & 164.11 & 163.82 & $\mathrm{~S}-\mathrm{C} \mathrm{2p1/2}$ \\
\hline
\end{tabular}

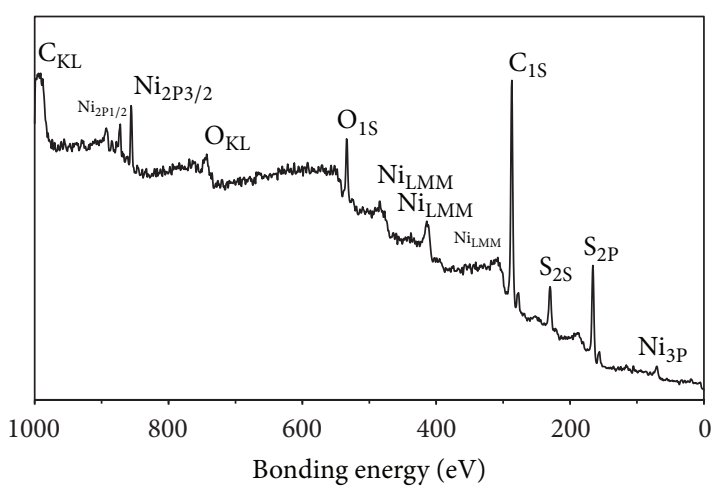

FIGURE 2: Wide-scan XPS spectrum of $\left[\mathrm{Ni}(\mathrm{cpdt})_{2}\right]$ complex.

The S $2 \mathrm{p}$ band region shows a single broad peak in $162 \mathrm{eV}$, with a FWHM $=2.6 \mathrm{eV}$ by the presence of the $2 \mathrm{p}_{1 / 2}$ and $2 \mathrm{p}_{3 / 2}$ core levels as well as two different sulfur atoms, expected by the ligand structure (Table 2). The peak separation of each $\mathrm{S} 2 \mathrm{p}$ peak is about 0.92 and $1.06 \mathrm{eV}$. The peaks at 161.12 and 163.06 correspond to the $2 \mathrm{p}_{3 / 2}$ core level and correspond to $\mathrm{S}-\mathrm{C}$ and $\mathrm{S}=\mathrm{C}$, respectively. The $\mathrm{O}$ 1s spectrum shows a broad peak centered at $530 \mathrm{eV}$ with a $\mathrm{FWHM}=2.9 \mathrm{eV}$, being in accord with the presence of more than one species. Gaussian deconvolution of $\mathrm{O} 1 \mathrm{~s}$ spectrum shows two peaks at 530.1 and $531.3 \mathrm{eV}$ (Table 2) which were assigned to a $\mathrm{O}-\mathrm{C}$ and $\mathrm{O}=\mathrm{C}$ moieties, respectively. Ketoenolate resonance is proved by the presence of these peaks and the same intensity of both gives further evidence of $\pi$-delocalization on the chelated ring.

3.2. Preparation of 2. One-dimensional coordination polymer was obtained in a straightforward process, from the synthesis of $\mathbf{1}$ and bpy in chloroform media. The color change from orange to light yellow was the initial evidence of its presence. The FTIR spectrum of $\mathbf{2}$ shows the signals associated with bpy bridge at 2954, 1575, 1483, 1375, and $625 \mathrm{~cm}^{-1}$ towards low wavenumbers respecting the free ligand, due to the nickel coordination. The vibrational energy decreases, probably due to the slight electron density from the $\sigma$-donation of the bpy. When the UV-vis spectra of $\mathbf{1}$ and 2 in $\mathrm{CHCl}_{3}$ were compared (Figure 1), both of them contain the same bands with a general hypochromic effect on the former, associated with the coordination of the bpy molecule. The main changes were in the visible region with a blue shift of LMCT band at $379 \mathrm{~nm}$, respecting those of $\mathbf{1}$ $(383 \mathrm{~nm})$. The slight decrement of the LMCT energy comes

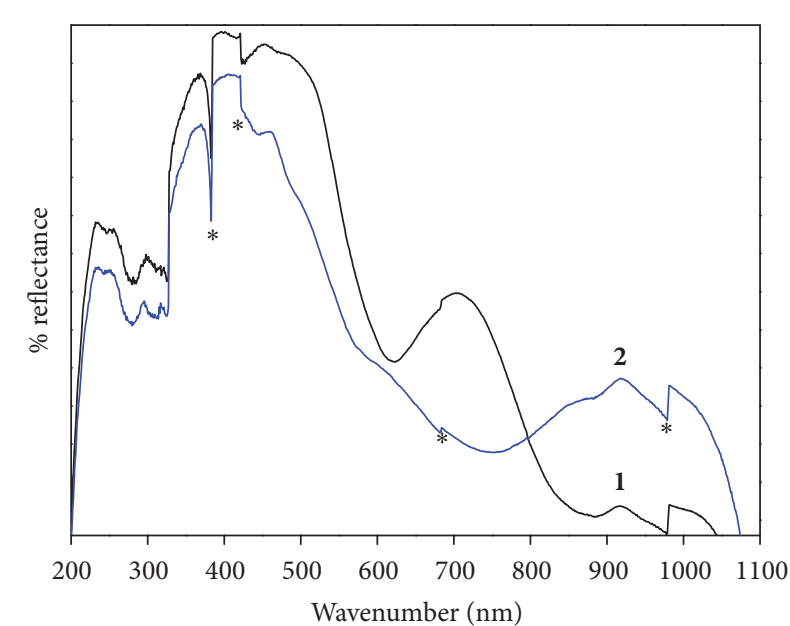

FIgURE 3: Absorption spectra of $\mathbf{1}$ and $\mathbf{2}$ by Diffuse Reflectance spectroscopy; * systematic signals associated with the nature of the spectrophotometer.

from the minor molecular orbital energy associated with the metal center, from the pyridine coordination. The solid spectrum shows a notable difference respecting precursor (Figure 3). The band LMCT at $459 \mathrm{~nm}$ is notably red shifted from $1(449 \mathrm{~nm})$, similar to similar systems [23]. Three more bands were observed at 571, 886, 922 and $955 \mathrm{~nm}$, which were assigned to the transitions ${ }^{3} \mathrm{~T}_{1 \mathrm{~g}}(\mathrm{P}) \leftarrow{ }^{3} \mathrm{~A}_{2 \mathrm{~g}}\left(\nu_{1}\right)$, ${ }^{3} \mathrm{~T}_{1 \mathrm{~g}}(\mathrm{~F}) \leftarrow{ }^{3} \mathrm{~A}_{2 \mathrm{~g}}\left(\nu_{2}\right)$, and ${ }^{3} \mathrm{~T}_{2 \mathrm{~g}}(\mathrm{~F}) \leftarrow{ }^{3} \mathrm{~A}_{2 \mathrm{~g}}\left(\nu_{3}\right)$, respectively, in an octahedral environment around the nickel ion [24-28], due to the coordination of two bipyridyl molecules.

The XPS spectrum of $\mathbf{2}$ (Table 2) shows the decrease on $S 2 p$ binding energies respecting 1 complex (Table 2) due to the small nuclear effective charge of the sulfur atom with bpy coordination. The $2 \mathrm{p}_{3 / 2}$ nickel signal shows a slight increase on $\mathrm{BE}$ with bpy coordination; this might be due to a decrease of its electron density. These facts could be related to the $\pi$ back donation of nickel to S-donor ligand, for the $\mathrm{N}$-donor ligand, attached to metal center.

No crystals of $\mathbf{1}$ and $\mathbf{2}$ suitable for single crystal were obtained, but PXRD analyses were performed. The powder pattern of $\mathbf{2}$ has a different phase than those observed for bpy and $\mathbf{1}$ (Figure 4) confirming a new phase, different to those. The diffractogram of $\mathbf{1}$ shows broader peaks, probably due to a less ordered solid, than those narrow peaks of 2 , which could be associated with a higher ordered solid structure. 


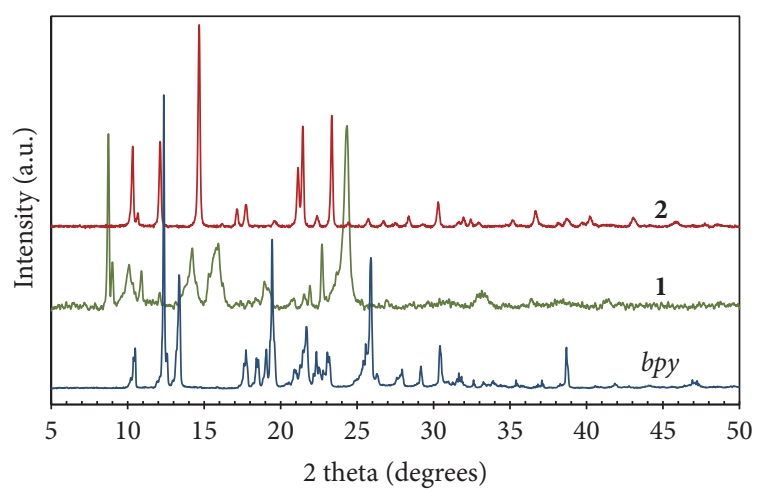

FIgURE 4: X-ray powder diffractograms of 1 and 2 . The mixture of 1 and bpy phases is not observed in the polymer diffraction pattern.
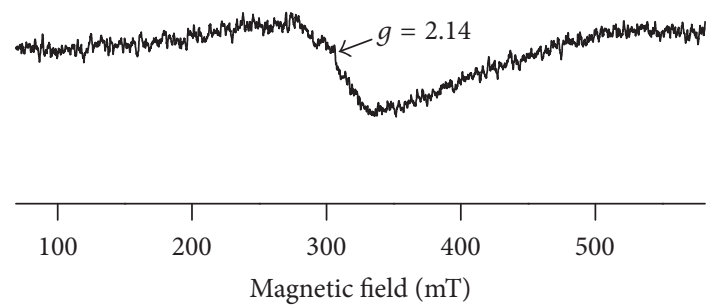

FIGURE 5: ESR spectra at $300 \mathrm{~K}$ of powdered sample of $\mathbf{1 .}$

The ESR analysis of $\mathbf{2}$ displays a broad singlet centered at $g=2.14$ (Figure 5), corresponding to a paramagnetic center of nickel(II) $[29,30]$. The line shape of the wide spectrum is associated with $\mathrm{Ni}$ (II) centers with $s=1$ [31] and magnetic interactions among them are present [32]. Wide endings of the spectrum show that the interactions are present even before applying the magnetic field and at higher frequencies than the allowed for the ESR spectrometer.

The polymeric structure of $\mathbf{2}$ was confirmed by its magnetic behavior. Figure 6 shows the temperature dependence of magnetic susceptibility of 2 at 1000 Oe applied field. The values of magnetic susceptibility slightly increase with the decrease of the temperature, from 300 to $34 \mathrm{~K}$. The magnetization is drastically enhanced below $30 \mathrm{~K}$, showing a tendency towards a lower antiferromagnetism at lower temperatures. The magnetization at high temperatures strongly agrees with Curie-Weiss law, as could be seen in $1 / \chi$ versus $T$ curve (Figure 6) [33]. The fitting result has $\theta=-99 \mathrm{~K}$ and $C$ $=0.375 \mathrm{~K} \mathrm{~mol}^{-1}$ values. The negative value of $\theta$ suggests an antiferromagnetic behavior of 2 . A $J$ value was calculated through the Weiss constant using the molecular-field theory (MFT) [33], affording an average coupling constant $J=$ $-8.63 \mathrm{~cm}^{-1}$, when $s=1$ and $z=6$ (coordination magnetic number) were used.

The temperature dependence of the effective magnetic moment (Figure 7) shows at $300 \mathrm{~K}$ a value of $\boldsymbol{\mu}_{\text {eff }}=1.52 \mu_{B}$, which is lower than those spin only values calculated for $s=1 / 2\left(1.73 \mu_{B}\right)$ and $s=1\left(2.83 \mu_{B}\right)$, confirming the antiferromagnetic behavior of the polymer. The value of $\mu_{\text {eff }}$ decreases linearly as the temperature decrease up to $\sim 35 \mathrm{~K}$. At this point, $\mu_{\mathrm{eff}}$ increases with temperature, up to a maximum

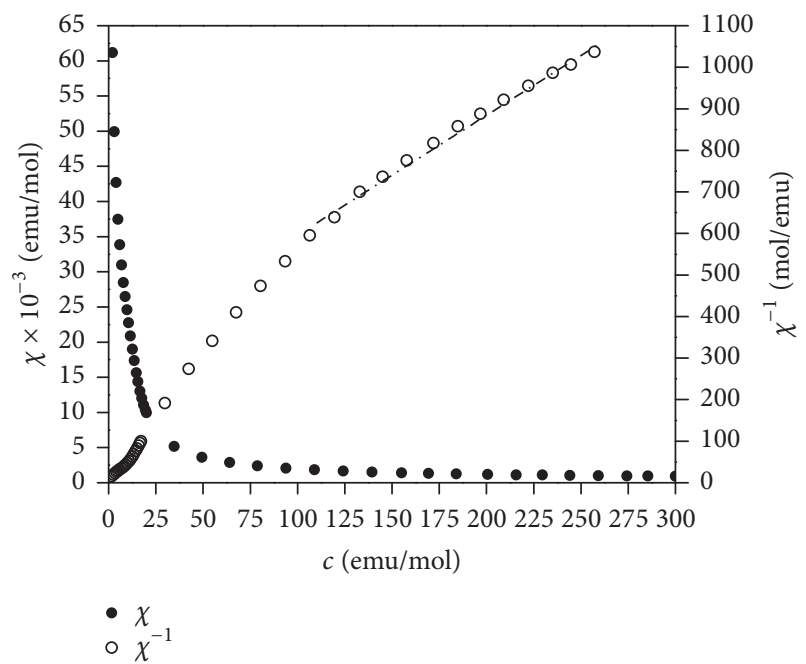

FIgURE 6: Temperature dependence of $\chi$ for 2 (filled circles) and Curie plot (open circles) with the best fit to Curie-Weiss law (dotted line) at 1000 Oe applied field.

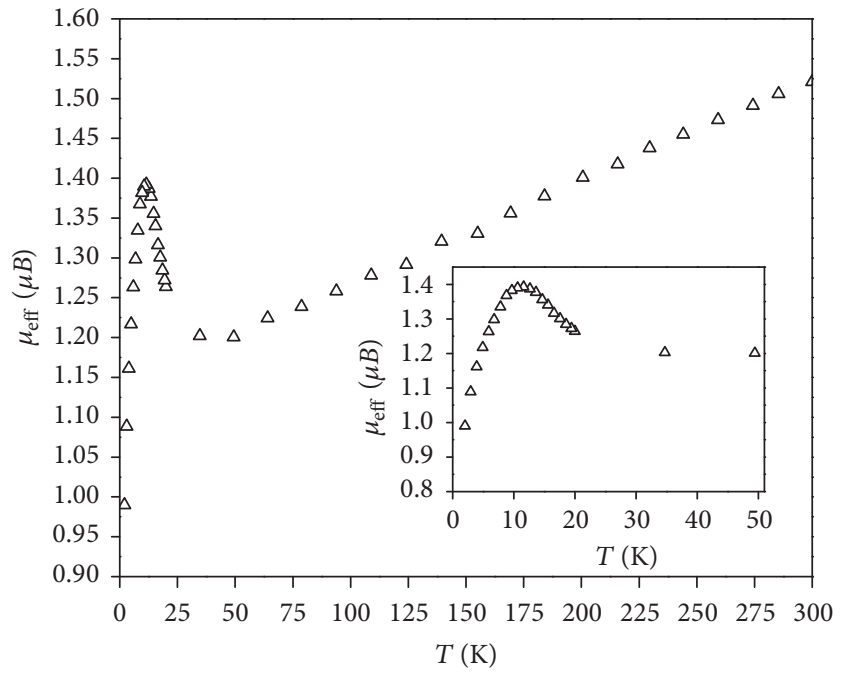

FIgURE 7: Effective magnetic moment $\left(\mu_{\text {eff }}\right)$ versus $\mathrm{T}$ for 2 at a magnetic field of 1000 Oe.

at $\sim 12 \mathrm{~K}$ decreasing at the lowest temperatures. This is a typical antiferromagnetic exchange behavior with a Neel temperature at $12 \mathrm{~K}$.

\section{Conclusions}

The coordination compound $\mathbf{1}$ was obtained following the reported methodology. The spectroscopy characterization allows us to propose in a square planar conformation, feasible to prepare a $1 \mathrm{D}$ coordination polymer bridging by bpy. The complex shows electron delocalization over the chelated ring and a diamagnetic behavior, as seen in XPS analyses. The straightforward synthesis of the polymer yields a compound with different physicochemical and structural properties than initial complex. In solution compared to in solid state, the $\mathrm{CP}$ was stable, and the solid has a different phase than the 
precursor complex. The paramagnetism of $\mathbf{2}$ is established at $T>100 \mathrm{~K}$. These results aim to propose the bridge of bipyridyl molecules within $\mathbf{1}$, confirming the presence of a $1 \mathrm{D}$ coordination compound. Importantly, further crystallization techniques are in progress to confirm the molecular structure of the polymers $\mathbf{1}$ and $\mathbf{2}$.

\section{Conflicts of Interest}

The authors declare that there are no conflicts of interest regarding the publication of this article.

\section{Acknowledgments}

This research was supported by project SIEA-UAEMex 3576/ 2013 and scholarship (Ricardo Rosas-Reyes) by CONACYT no. 364553. The authors thank the invaluable technical assistance of Professor Roberto Escudero, Nieves Zavala-Segovia, Alejandra Núñez-Pineda, Lizbeth Triana-Cruz, Gustavo López-Tellez, and Citlali Martínez-Soto. Thanks are due to Dr. Samuel Hernández-Anzaldo for the English revision of the manuscript.

\section{References}

[1] R. J. Kuppler, D. J. Timmons, Q.-R. Fang et al., "Potential applications of metal-organic frameworks," Coordination Chemistry Reviews, vol. 253, no. 23-24, pp. 3042-3066, 2009.

[2] J. Lee, O. K. Farha, J. Roberts, K. A. Scheidt, S. T. Nguyen, and J. T. Hupp, "Metal-organic framework materials as catalysts," Chemical Society Reviews, vol. 38, no. 5, pp. 1450-1459, 2009.

[3] D. Farrusseng, S. Aguado, and C. Pinel, "Metal-organic frameworks: Opportunities for catalysis," Angewandte Chemie International Edition, vol. 48, no. 41, pp. 7502-7513, 2009.

[4] S. Shimomura, S. Bureekaew, and S. Kitagawa, "Molecular Networks SE - 8," in Molecular Networks SE - 8, M. W. Hosseini, Ed., pp. 96-106, Springer Berlin Heidelberg, 2009.

[5] S. Horike, S. Shimomura, and S. Kitagawa, "Soft porous crystals," Nature Chemistry, vol. 1, no. 9, pp. 695-704, 2009.

[6] A. Morozan and F. Jaouen, "Metal organic frameworks for electrochemical applications," Energy \& Environmental Science, vol. 5, no. 11, pp. 9269-9290, 2012.

[7] D. V. Soldatov, P. Tinnemans, G. D. Enright, C. I. Ratcliffe, P. R. Diamente, and J. A. Ripmeester, "Modified metal dibenzoylmethanates for soft supramolecular materials: Extension to oligomeric and polymeric host receptors with nanosized void spaces," Chemistry of Materials, vol. 15, no. 20, pp. 3826-3840, 2003.

[8] M. Hanack, S. Deger, and A. Lange, "Bisaxially coordinated macrocyclic transition metal complexes," Coordination Chemistry Reviews, vol. 83, no. C, pp. 115-136, 1988.

[9] H. Schultz, H. Lehmann, M. Rein, and M. Hanack, "Phthalocyaninatometal and related complexes with special electrical and optical properties," in Metal Complexes with Tetrapyrrole Ligands II SE - 2, J. W. Buchler, Ed., vol. 74 of Structure and Bonding, pp. 41-146, Springer Berlin Heidelberg, Berlin, Heidelberg, Germany, 1991.

[10] M. Žinić, J. L. Atwood, and J. W. Steed, Encyclopedia of Supramolecular Chemistry, pp. 1139-1149, Marcel Dekker, New York, NY, USA, 2004.
[11] J. P. Collman, J. T. McDevitt, G. T. Yee et al., "Conductive polymers derived from iron, ruthenium, and osmium metalloporphyrins: The shish-kebab approach," Proceedings of the National Acadamy of Sciences of the United States of America, vol. 83, no. 13, pp. 4581-4585, 1986.

[12] D. V. Soldatov, "Soft organic and metal-organic frameworks with porous architecture: From wheel-and-axle to ladder-andplatform design of host molecules," Journal of Chemical Crystallography, vol. 36, no. 11, pp. 747-768, 2006.

[13] J. Yoshida, S.-I. Nishikiori, and R. Kuroda, "Formation of 1 $\mathrm{D}$ and $3 \mathrm{D}$ coordination polymers in the solid state induced by mechanochemical and annealing treatments: bis(3-cyanopentane-2,4-dionato) metal complexes.," Chemistry (Weinheim an der Bergstrasse, Germany), vol. 14, no. 34, pp. 10570-10578, 2008.

[14] Y.-B. Dong, J.-P. Ma, M. D. Smith et al., “One-dimensional coordination polymers generated from an oxadiazole-containing N,N/-bipyridine-type ligand and $\mathrm{Cu}(\mathrm{II})$ salts," Solid State Sciences, vol. 5, no. 4, pp. 601-610, 2003.

[15] G. Dorange, R. Kergoat, and J. E. Guerchais, Bulletin de La Société Chimique de France 11, vol. 11, p. 3835, 1969.

[16] R. Mayer and H. Hartmann, "Schwefelheterocyclen und Vorstufen, XXXVIII. Reaktionsweise des Trimethylentrithions (4.5-Dihydro-6H-cyclopenta[d]1.2-dithiolthions-(3)) und seiner Salze," Chemische Berichte, vol. 97, no. 7, pp. 1886-1895, 1964.

[17] I. García-Orozco, M. C. Ortega-Alfaro, J. G. López-Cortés, R. A. Toscano, and C. Alvarez-Toledano, "Synthesis and characterization of novel dinuclear copper(I) complexes. Dimerization of $\left[\mathrm{CuL}\left(\mathrm{PPh}_{3}\right)_{2}\right](\mathrm{L}=$ methyl 3-hydroxy-3-(p-R-phenyl)-2-propenedithioate)," Inorganic Chemistry, vol. 45, no. 4, pp. 17661773,2006

[18] M. Asadi, K. Mohammadi, S. Esmaielzadeh, B. Etemadi, and H. K. Fun, "Some new Schiff base ligands giving a NNOS coordination sphere and their nickel(II) complexes: Synthesis, characterization and complex formation," Polyhedron, vol. 28, no. 8, pp. 1409-1418, 2009.

[19] A. R. Latham, V. C. Hascall, and H. B. Gray, "The electronic structures and spectral properties of the square-planar dithiooxalate complexes of Nickel(II), Palladium (II), Platinum (II), and Gold (III)," Inorganic Chemistry, vol. 4, no. 6, pp. 788-792, 1965.

[20] W. R. Mason III and H. B. Gray, "Electronic structures of squareplanar complexes," Journal of the American Chemical Society, vol. 90, no. 21, pp. 5721-5729, 1968.

[21] S. S. Konstantinović, B. C. Radovanović, Ž. Cakić, and V. M. Vasić, "Synthesis and characterization of $\mathrm{Co}(\mathrm{II}), \mathrm{Ni}(\mathrm{II})$, $\mathrm{Cu}$ (II) and $\mathrm{Zn}$ (II) complexes with 3-salicylidenehydrazono-2indolinone," Journal of Serbian Chemical Society, vol. 68, no. 8-9, pp. 641-647, 2003.

[22] L. Beyer, R. Kirmse, J. Stach, R. Szargan, and E. Hoyer, "Metallkomplexe des Benzoyldithioessigsäuremethylesters und des N-Benzoylamino-dithiokohlensäureethylesters: Darstellung und Charakterisierung, ESCA- und EPR-Untersuchungen [1]," ZAAC - Journal of Inorganic and General Chemistry, vol. 476, Zeitschrift Für Anorganische Und Allgemeine Chemie, no. 5, pp. 7-15, 1981.

[23] O. Rotthaus, F. Thomas, O. Jarjayes, C. Philouze, E. SaintAman, and J.-L. Pierre, "Valence tautomerism in octahedral and square-planar phenoxyl-nickel(II) complexes: Are imino nitrogen atoms good friends?" Chemistry - A European Journal, vol. 12, (Weinheim an Der Bergstrasse, Germany), no. 26, pp. 69536962, 2006. 
[24] M. G. Babashkina, D. A. Safin, K. Robeyns, and Y. Garcia, "A neutral 1D coordination polymer constructed from the niii complex of the n-phosphorylated thiourea phnhc(s)nhp(o)(oph) $)_{2}$ and pyrazine: A single-source precursor for nickel nanoparticles," European Journal of Inorganic Chemistry, vol. 2015, no. 7, pp. 1160-1166, 2015.

[25] N. H. Al-Shaalan, "Synthesis, characterization and biological activities of $\mathrm{Cu}$ (II), $\mathrm{Co}(\mathrm{II}), \mathrm{Mn}(\mathrm{II}), \mathrm{Fe}(\mathrm{II})$, and UO 2(VI) complexes with a new Schiff base hydrazone: O-hydroxyacetophenone-7-chloro-4-quinoline hydrazone," Molecules, vol. 16, no. 10, pp. 8629-8645, 2011.

[26] K. B. Gudasi, S. A. Patil, R. S. Vadavi, R. V. Shenoy, and M. S. Patil, "Synthesis and spectral studies of $\mathrm{Cu}(\mathrm{II}), \mathrm{Ni}(\mathrm{II}), \mathrm{Co}(\mathrm{II})$, $\mathrm{Mn}(\mathrm{II}), \mathrm{Zn}(\mathrm{II})$ and Cd(II) complexes of a new macroacyclic ligand N,N/-bis(2- benzothiazolyl)-2,6-pyridinedicarboxamide," Journal of the Serbian Chemical Society, vol. 71, no. 5, pp. 529$542,2006$.

[27] R. Srinivasan, I. Sougandi, R. Venkatesan, and P. S. Rao, "Synthesis and room temperature single crystal EPR studies of a dinickel complex having an $\mathrm{Ni}_{2}(\mu \text {-phenoxide })_{2}^{2+}$ unit supported by a macrocyclic ligand environment $\left[\mathrm{Ni}_{2}(\mathrm{~L})_{2}\left(\mathrm{OClO}_{3}\right)_{2}\right][\mathrm{L}=$ 2-[(4-methyl-pyridin-2-ylimino)-methyl]-phenol]," Journal of Chemical Sciences, vol. 115, no. 2, pp. 91-102, 2003.

[28] D. Coucouvanis and J. P. Fackler Jr., "Square-planar sulfur complexes. VI. Reactions of bases with xanthates, dithiocarbamates, and dithiolates of nickel(II)," Inorganic Chemistry, vol. 6, no. 11, pp. 2047-2053, 1967.

[29] M. Dey, J. P. Chinta, G. J. Long, and P. Rao, "Synthesis and characterization of complexes of $\mathrm{Fe}(\mathrm{III}), \mathrm{Co}(\mathrm{III}), \mathrm{Ni}(\mathrm{II}), \mathrm{Cu}(\mathrm{II})$, $\mathrm{Zn}(\mathrm{II})$ and $\mathrm{UO}_{2}^{2+}$ with $p$-tert-butylcalix[4] arene bearing two iminependants linked through salicylyl moiety at thelower rim," Indian Journal of Chemistry, vol. 48A, no. 11, pp. 1484-1491, 2009.

[30] G. Bai, P. Wei, and D. W. Stephan, "A $\beta$-diketiminato-nickel(II) synthon for nickel(I) complexes," Organometallics, vol. 24, no. 24, pp. 5901-5908, 2005.

[31] F. T. Vieira, G. M. de Lima, J. L. Wardell, S. M. S. V. Wardell, K. Krambrock, and A. F. D. C. Alcântara, "Synthesis and characterization of [chloro2 $(1 \mathrm{H})$-pyridinethione-Stris(pyridin2-ylthiolato)methyl-C,N,N $\left.N^{\prime} \mathrm{N}^{\prime \prime}\right]$ nickel(II)],

[Ni(TPTM)(SPyH)Cl]," Journal of Organometallic Chemistry, vol. 693, no. 11, pp. 1986-1990, 2008.

[32] I. M. Krygin and A. D. Prokhorov, "Spin-spin interaction of $\mathrm{Ni}^{2+}$ ions in $\mathrm{ZnSiF}_{6} \cdot 6 \mathrm{H}_{2} \mathrm{O}$," Physics of the Solid State, vol. 41, no. 9, pp. 1469-1475, 1999.

[33] R. L. Carlin, Magnetochemistry, Springer Berlin Heidelberg, Berlin, Heidelberg, Germany, 1st edition, 1986. 

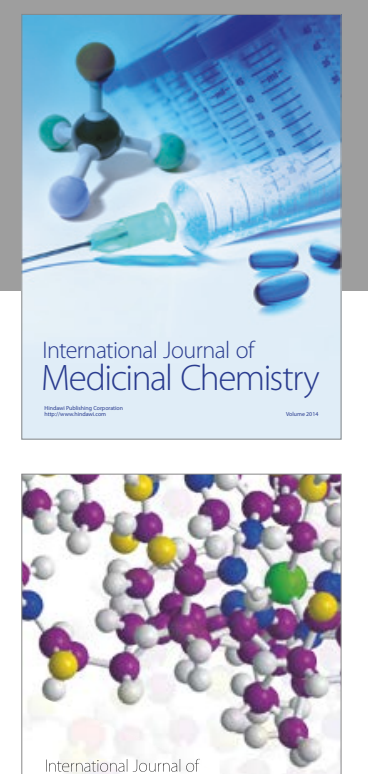

Carbohydrate Chemistry

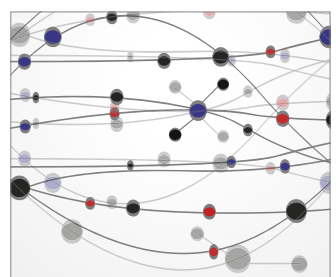

The Scientific World Journal
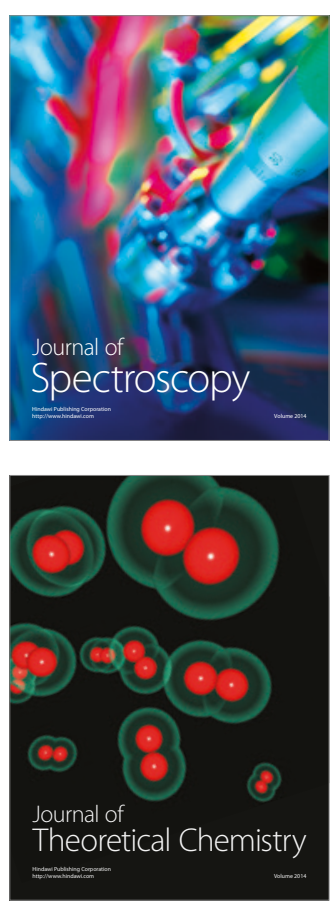
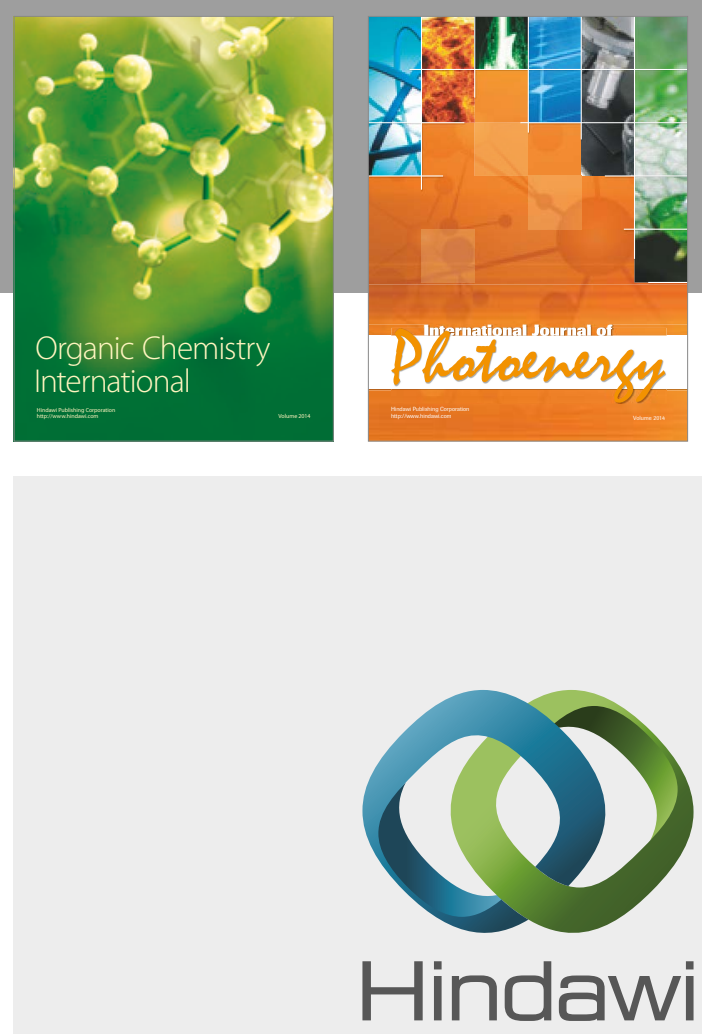

Submit your manuscripts at

https://www.hindawi.com

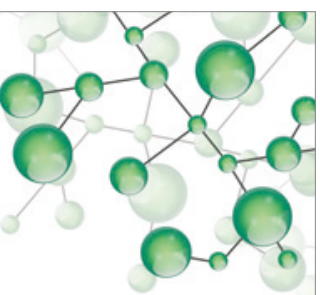

International Journal of

Inorganic Chemistry

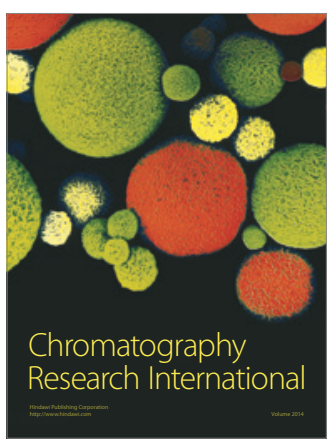

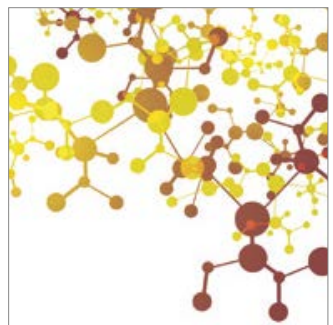

Applied Chemistry
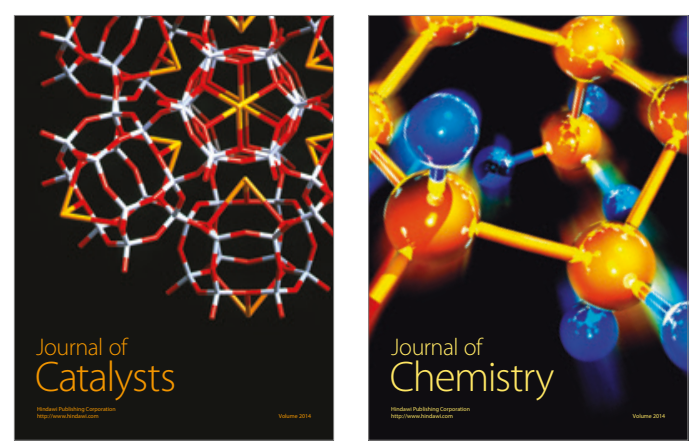
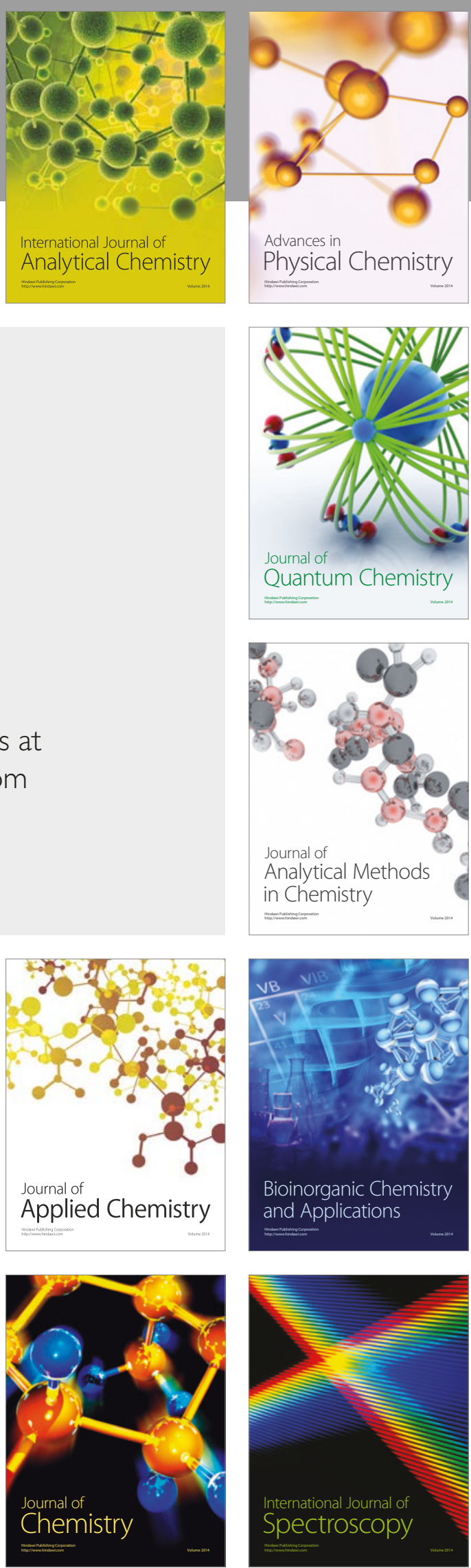